\title{
Silver Nanoparticles for Olefin Production: New Insights into the Mechanistic Description of Propyne Hydrogenation
}

\author{
Gianvito Vilé, ${ }^{[a]}$ David Baudouin, ${ }^{[b]}$ Ioannis N. Remediakis, ${ }^{[c]}$ Christophe Copéret, ${ }^{*[b]}$ \\ Núria López, ${ }^{*[d]}$ and Javier Pérez-Ramírez ${ }^{*[a]}$
}

\begin{abstract}
The gas-phase partial hydrogenation of propyne was investigated over supported Ag nanoparticles (2-20 nm in diameter) prepared by using different deposition methods, activation conditions, loadings, and carriers. The excellent selectivities to propene attained over the catalysts, exceeding $90 \%$, are independent of the particle size but the activity is maximal over approximately $4.5 \mathrm{~nm} \mathrm{Ag}$ particles. Certain kinetic fingerprints of $\mathrm{Ag}$, such as the positive dependence on the alkyne pressure, the relatively low reaction order in $\mathrm{H}_{2}$, and the low apparent activation energy, deviate from those of conventional hydrogenation metals such as $\mathrm{Pd}$ and $\mathrm{Ni}$, questioning the applicability of the classical Horiuti-Polanyi scheme. Periodic dispersion-cor-
\end{abstract}

rected density functional theory (DFT-D) calculations and microkinetic analysis demonstrate the occurrence of an associative mechanism, which features the activation of $\mathrm{H}_{2}$ on the adsorbed propyne at structural step sites. By using the atomistic Wulff model, the number of B5 sites available on the Ag nanoparticles was estimated to be maximal in the size range of 3.5$4.7 \mathrm{~nm}$. The rate of propene production correlates with the density of B5 sites, which suggests that the latter are potential active centers for the reaction. This alternative pathway broadens the mechanistic diversity of hydrogenation reactions over metal surfaces and opens new directions for understanding metals that do not readily activate $\mathrm{H}_{2}$.

\section{Introduction}

The selective hydrogenation of targeted functional groups over heterogeneous catalysts is one of the most studied families of reactions in catalysis and plays a central role in multiple industrial sectors. ${ }^{[1,2]}$ One example is the Pd-catalyzed partial hydrogenation of unsaturated hydrocarbons in the gas or liquid phase, which is a crucial step for the purification of olefin streams and for the manufacture of fine chemicals. ${ }^{[3]}$ The practical relevance of these processes has led to intense efforts to improve the fundamental understanding of the reaction,

[a] G. Vilé, Prof. J. Pérez-Ramírez

Department of Chemistry and Applied Biosciences

Institute for Chemical and Bioengineering

ETH Zurich

Wolfgang-Pauli-Strasse 10, CH-8093 Zurich (Switzerland)

E-mail:jpr@chem.ethz.ch

[b] Dr. D. Baudouin, Prof. C. Copéret

Laboratory of Inorganic Chemistry

Department of Chemistry and Applied Biosciences

ETH Zurich

Wolfgang-Pauli-Strasse 10, CH-8093 Zurich (Switzerland)

E-mail:ccoperet@inorg.chem.ethz.ch

[c] Prof. I. N. Remediakis

Department of Materials Science and Technology

University of Crete

GR-71003 Heraklion (Greece)

[d] Prof. N. López

Institute of Chemical Research of Catalonia, ICIQ

Av. Països Catalans 16, E-43007 Tarragona (Spain)

E-mail:nlopez@iciq.es

Supporting information for this article is available on the WWW under http://dx.doi.org/10.1002/cctc.201300569. and many catalytic systems have been studied with the purpose of maximizing the alkene selectivity. ${ }^{[4-12]}$ The prototypical mechanism describing the heterogeneously-catalyzed hydrogenation of unsaturated hydrocarbons, referred to as the Horiuti-Polanyi (HP) scheme, involves the dissociation of molecular $\mathrm{H}_{2}$ on the metal surface followed by the addition of $\mathrm{H}$ atoms to the adsorbed organic moiety. ${ }^{[13]}$ Originally proposed for the hydrogenation of ethylene and benzene over nickel, this scheme was extended to alkynes and dienes over $\mathrm{Pd}$ and $\mathrm{Ni}^{[10]}$ and served as a guide for understanding double bond isomerization and deuterium scrambling. ${ }^{[14]}$ The HP scheme has also been applied to metals with limited $\mathrm{H}_{2}$ splitting ability, as shown for propyne hydrogenation over gold and copper nanoparticles. ${ }^{[10]}$ Over these metals, the dissociation of $\mathrm{H}_{2}$ is improved at steps and kinks, owing to electronic and geometric effects, ${ }^{[10,15]}$ which minimizes over-hydrogenation, leading to a remarkable olefin yield.

Ag shows the lowest reactivity toward $\mathrm{H}_{2} i^{[16-18]}$ its dissociation features large activation barriers even at low-coordinated surface sites. ${ }^{[19]}$ Nevertheless, Sárkány and Révay studied the hydrogenation of ethyne over $\mathrm{SiO}_{2}-$ and $\mathrm{TiO}_{2}$-supported $\mathrm{Ag}$ nanoparticles (4-8 $\mathrm{nm}$ ) and reported full selectivity to ethene at a low degree of ethyne conversion (3-13\%). ${ }^{[20]}$ Although the work demonstrated the highly selective character of $\mathrm{Ag}$ in alkyne hydrogenation, no mechanistic and kinetic understanding exists thus far and the difficulty to dissociate $\mathrm{H}_{2}$ on $\mathrm{Ag}$ questions the validity of the HP scheme.

An alternative mechanism, observed in organometallic chemistry, homogeneous catalysis, and isolated metal centers 
on oxide surfaces, involves the cleavage of the $\mathrm{H}-\mathrm{H}$ bond via the direct activation of molecular $\mathrm{H}_{2}$ on the adsorbed hydrocarbon-metal complex (hereafter referred to as associative mechanism). ${ }^{[21,22]}$ In heterogeneous catalysis, this scheme was speculated for the hydrogenation of norbornadiene and protoadamantanone over $\mathrm{Au} / \mathrm{SiO}_{2}{ }^{[23]}$ but no supporting evidence was provided. The weak interaction between $\mathrm{H}_{2}$ and $\mathrm{Ag}$ justifies a detailed mechanistic and kinetic analysis on this alternative pathway.

Herein, we study the partial hydrogenation of propyne to propene over supported Ag nanoparticles with variable particle size $(2-20 \mathrm{~nm})$, attained by modification of different preparation variables. Olefin production over the catalysts is favored (up to $93 \%$ selectivity), even at a high degree of alkyne conversion. By combining a large set of systematic steady-state catalytic tests over well-characterized samples, DFT calculations, and microkinetic analyses, we demonstrate that $\mathrm{H}_{2}$ splitting on the alkyne adsorbate is the key elementary step of the selective hydrogenation of alkyne on Ag. The activity is maximal over approximately $4.5 \mathrm{~nm} \mathrm{Ag}$ particles, which correlates with the highest amount of B5 sites on such particles evaluated by using the atomistic Wulff method. The development of this pathway provides new views on hydrogenation mechanisms over metal surfaces beyond the classical dissociative pathway proposed by Horiuti and Polanyi nearly 80 years ago.

\section{Results and Discussion}

\section{Catalyst characterization}

The characterization data of selected Ag-based catalysts are listed in Table 1. The silver content in the samples matches the nominal loading. The BET surface area of the catalysts after the deposition of $0.5-5 \mathrm{wt} \% \mathrm{Ag}$ is extremely close to the specific surface area of the corresponding support. Transmission electron microscopy (TEM) was used to assess the distribution of Ag nanoparticles and to estimate an average value of metal dispersion. The representative transmission electron micrographs of exemplary $1 \mathrm{wt} \% \mathrm{Ag} / \mathrm{SiO}_{2}$ catalysts with different $\mathrm{Ag}$ dispersions as a consequence of $\mathrm{H}_{2}$ activation after spray depo-

\begin{tabular}{|lllllll|}
\hline \multicolumn{2}{|l}{ Table 1. Characterization data of selected catalysts. } & & & \\
Catalyst & Method & Activation & $\begin{array}{l}\text { Ag content } \\
{[\mathrm{wt} \%]}\end{array}$ & $\begin{array}{l}\mathrm{S}_{\mathrm{BET}} \\
{\left[\mathrm{m}^{2} \mathrm{~g}^{-1}\right]}\end{array}$ & $\begin{array}{l}d_{\mathrm{Ag}}{ }^{[\mathrm{d}]} \\
{[\mathrm{nm}]}\end{array}$ & $\begin{array}{r}D^{[\mathrm{d}]} \\
{[\%]}\end{array}$ \\
\hline $0.5 \mathrm{wt} \% \mathrm{Ag} / \mathrm{SiO}_{2}$ & $\mathrm{SD}$ & $\mathrm{H}_{2}$ flow & 0.5 & $199(197)^{[\mathrm{cc}]}$ & - & - \\
$1 \mathrm{wt} \% \mathrm{Ag} / \mathrm{SiO}_{2}$ & $\mathrm{SD}$ & static air & 1.3 & 196 & $21.3 \pm 8.3$ & 5 \\
& & $\mathrm{H}_{2}$ flow & 1.3 & 196 & $4.4 \pm 3.1$ & 17 \\
& $\mathrm{FD}$ & $\mathrm{H}_{2}$ flow & 1.0 & 198 & $2.0 \pm 0.3$ & 75 \\
& $\mathrm{CD}$ & $\mathrm{H}_{2}$ flow & 1.0 & 195 & $4.6 \pm 1.6$ & 24 \\
$5 \mathrm{wt} \% \mathrm{Ag} / \mathrm{SiO}_{2}$ & $\mathrm{SD}$ & $\mathrm{H}_{2}$ flow & 4.9 & 186 & $6.2 \pm 3.3$ & 14 \\
$1 \mathrm{wt} \% \mathrm{Ag} / \mathrm{Al}_{2} \mathrm{O}_{3}$ & $\mathrm{SD}$ & $\mathrm{H}_{2}$ flow & 0.9 & $79(81)$ & $2.3 \pm 0.8$ & 49 \\
$1 \mathrm{wt} \% \mathrm{Ag} / \mathrm{TiO}_{2}$ & $\mathrm{SD}$ & $\mathrm{H}_{2}$ flow & 1.1 & $28(32)$ & $2.8 \pm 0.2$ & 45 \\
\hline
\end{tabular}

[a] $C D=$ impregnation followed by conventional drying; $F D=$ impregnation followed by freeze drying; SD = spray deposition. [b] Determined from inductively coupled plasma optical emission spectroscopy analysis. [c] BET surface area of the supports within parentheses. [d] Determined from TEM analysis.
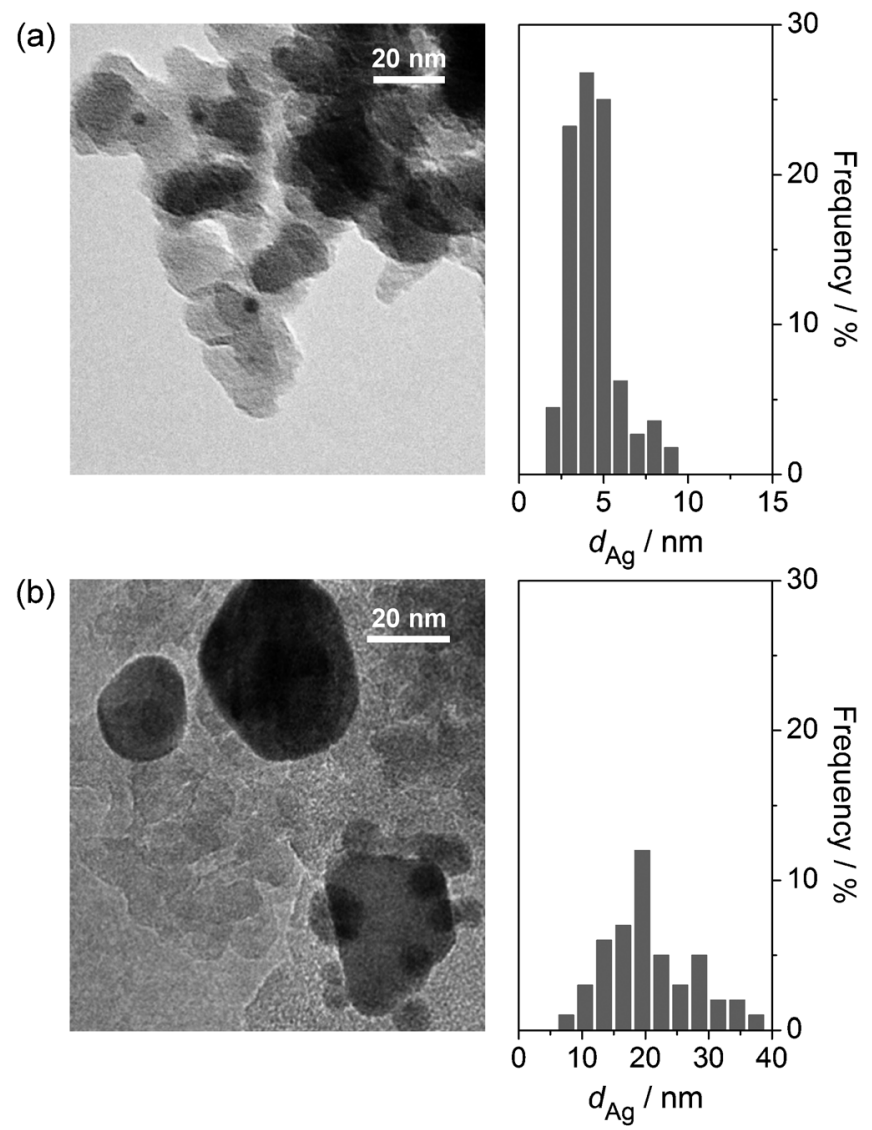

Figure 1. Transmission electron micrographs and particle size distributions of two representative $1 \mathrm{wt} \% \mathrm{Ag} / \mathrm{SiO}_{2}$ catalysts with different $\mathrm{Ag}$ dispersion. The catalysts were prepared by the spray deposition method followed by (a) activation in $\mathrm{H}_{2}$ flow at $473 \mathrm{~K}$ for $0.5 \mathrm{~h}$ or (b) calcination in static air at $573 \mathrm{~K}$ for $2 \mathrm{~h}$.

sition of the Ag precursor on the carrier are shown in Figure 1. Calcination in static air leads to a large average Ag particle size of approximately $20 \mathrm{~nm}$ ( $\mathrm{Ag}$ dispersion $=5 \%$ ) in contrast to the much smaller particles of $4.4 \mathrm{~nm}$ (Ag dispersion $=17 \%$ ) if the same spray-deposited catalyst is activated in flowing $\mathrm{H}_{2}$. The impregnation of $1 \mathrm{wt} \% \mathrm{Ag}$ on silica followed by conventional drying and $\mathrm{H}_{2}$ flow activation generates a catalyst with an $\mathrm{Ag}$ dispersion amounting to $24 \%$ and an average Ag particle size of $4.6 \mathrm{~nm}$. The higher dispersion value over the impregnated sample than over the spray-deposited sample is associated with the more uniform size distribution of the Ag nanoparticles in the impregnated sample. Ag particles of $c a$. $2 \mathrm{~nm}$ (Ag dispersion $=75 \%$ ) were obtained in the $1 \mathrm{wt} \% \mathrm{Ag} / \mathrm{SiO}_{2}$ catalyst prepared through impregnation followed by freeze drying and $\mathrm{H}_{2}$ flow activation. In fact, the rapid cooling of the precursor phase during freeze drying reduces the mobility of the liquid, minimizes particle segregation, and often provides a homogeneous powder of fairly uniform particle size. ${ }^{[24,25]} 1 \mathrm{wt} \% \mathrm{Ag} / \mathrm{Al}_{2} \mathrm{O}_{3}$ and $1 \mathrm{wt} \% \mathrm{Ag} / \mathrm{TiO} \mathrm{O}_{2}$ obtained through spray deposition and $\mathrm{H}_{2}$ flow activation also demonstrate highly dispersed nanoparticles 
centered at 2.3 and $2.8 \mathrm{~nm}$, respectively. The Ag loading moderately affects the dispersion: the average $\mathrm{Ag}$ particle size increases from 4.4 to $6.2 \mathrm{~nm}$ if the Ag content increases from 1 to $5 \mathrm{wt} \%$ over the $\mathrm{Ag} / \mathrm{SiO}_{2}$ catalyst prepared through spray deposition and $\mathrm{H}_{2}$ flow activation. Thus, it can be concluded that the stabilization of small Ag nanoparticles on the carriers requires rapid drying and flow activation conditions whereas the nature of the support, the silver loading, and the deposition method play a secondary role. The systematic characterization of the catalysts after the hydrogenation tests enabled us to conclude that Ag loading, catalyst textural properties, and $\mathrm{Ag}$ dispersion are not altered by the reaction (Figure S1).

\section{Propyne hydrogenation}

The effect of temperature (373-573 K) and $\mathrm{H}_{2} / \mathrm{C}_{3} \mathrm{H}_{4}$ ratio (5-25) on the performance of propyne hydrogenation was investigated over two representative Ag-based catalysts with different particle sizes (Figure 2). Figure $2 \mathrm{a}$ and $\mathrm{b}$ shows the effect of temperature and $\mathrm{H}_{2} / \mathrm{C}_{3} \mathrm{H}_{4}$ ratio over $1 \mathrm{wt} \% \mathrm{Ag} / \mathrm{SiO}_{2}$ prepared through spray deposition and $\mathrm{H}_{2}$ flow activation (Figure $1 \mathrm{a}$ ), whereas Figure $2 \mathrm{C}$ and $\mathrm{d}$ refers to the $\mathrm{SiO}_{2}$-supported $1 \mathrm{wt} \%$ catalyst prepared through spray deposition and calcination in static air (Figure $1 \mathrm{~b}$ ). Both the materials show an increase in propyne conversion with an increase in temperature. The selectivity to propene is practically unchanged $(\approx 90 \%)$ up to $473 \mathrm{~K}$, and the selectivity to the undesired products (propane and oligomers) does not exceed $10 \%$. Higher temperatures
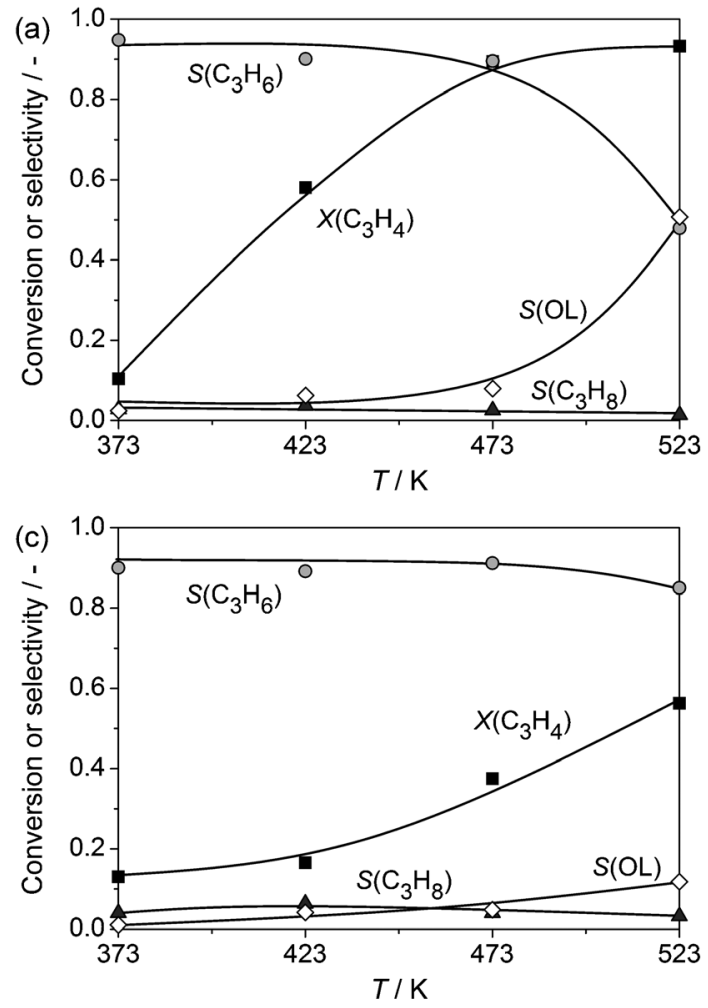

favor $\mathrm{C}-\mathrm{C}$ coupling reactions at the expense of the lower alkene selectivity. Regarding the effect of the reactants ratio, upon increasing the inlet partial $\mathrm{H}_{2}$ pressure, the conversion of propyne increases quasi-linearly; in addition, the selectivity to propene increases, which suggests that $\mathrm{H}_{2}$ activation is the rate-limiting step of the reaction. The selectivity to propane is very low $(<5 \%)$, even at $\mathrm{H}_{2} / \mathrm{C}_{3} \mathrm{H}_{4}=25$, and oligomers are produced at the lowest $\mathrm{H}_{2}$-to-hydrocarbon ratios. ${ }^{[26]}$ Despite different $\mathrm{Ag}$ dispersions in the two catalysts, the selectivity patterns are analogous; in contrast, the catalyst calcined in static air (Figure $2 \mathrm{c}$ and $\mathrm{d}$ ) shows a significantly low propyne conversion because of its larger (and less active) Ag particles.

All remaining catalysts were tested at $T=473 \mathrm{~K}$ and $\mathrm{H}_{2} /$ $\mathrm{C}_{3} \mathrm{H}_{4}=25$; Table 2 summarizes the effect of different preparation variables on the catalytic performance. The conversion of propyne increases with an increased Ag content, which reaches more than $90 \%$ at $1 \mathrm{wt} \% \mathrm{Ag}$. The plateau at higher loadings is due to the formation of larger Ag particles, which expose a minor number of surface atoms responsible for the catalytic process. The selectivity to propene is remarkably high (>90\%) regardless of the particle size, and the selectivity to propane and oligomers is less than $10 \%$ in all catalysts. It should be stressed that the high selectivity to propene is attained at a full degree of conversion, being significant for industrial purposes. The activation conditions during preparation also affect the catalyst performance. The increased Ag particle size upon calcination in static air leads to low alkyne conversion (31\%) at an alkene selectivity of $91 \%$. In contrast, the
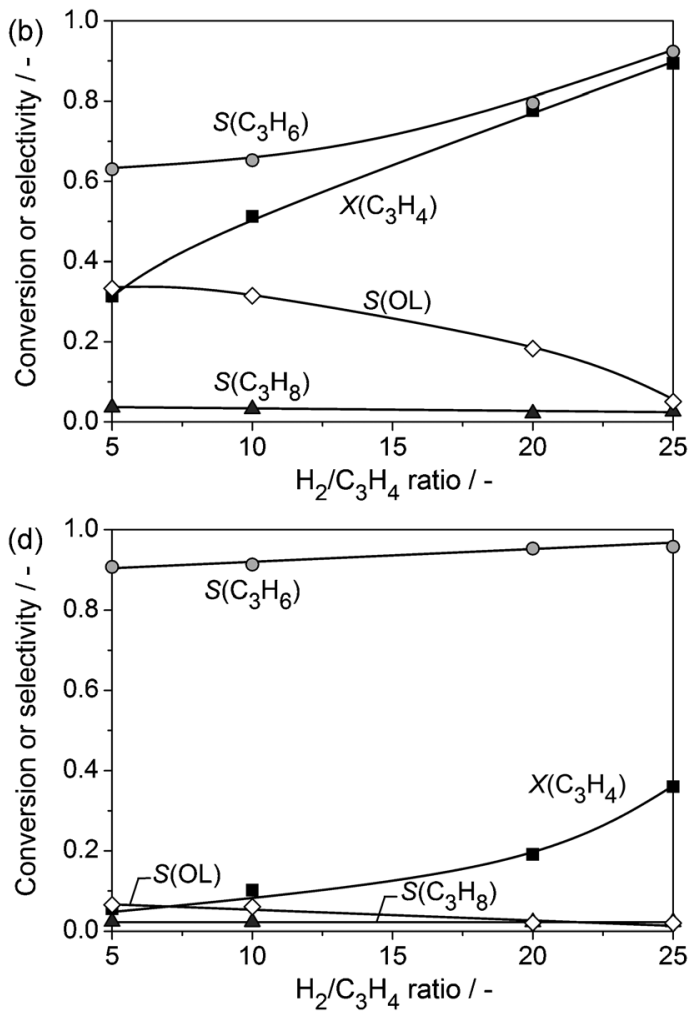

Figure 2. Propyne hydrogenation performance versus temperature (at $\mathrm{H}_{2} / \mathrm{C}_{3} \mathrm{H}_{4}=25$; left) and $\mathrm{H}_{2} / \mathrm{C}_{3} \mathrm{H}_{4}$ ratio (at $T=473 \mathrm{~K}$; right) over 1 wt $\%$ Ag/SiO 2 prepared by spray deposition followed by $(\mathrm{a}, \mathrm{b})$ activation in $\mathrm{H}_{2}$ flow at $473 \mathrm{~K}$ for $0.5 \mathrm{~h}$ or $(\mathrm{c}, \mathrm{d})$ calcination in static air at $573 \mathrm{~K}$ for $2 \mathrm{~h}$. Other reaction conditions: $\tau=1 \mathrm{~s}$ and $P=1$ bar. 


\begin{tabular}{|c|c|c|c|c|c|c|}
\hline Catalyst & Method & Activation & $\begin{array}{l}X\left(\mathrm{C}_{3} \mathrm{H}_{4}\right) \\
{[-]}\end{array}$ & $\begin{array}{l}S\left(\mathrm{C}_{3} \mathrm{H}_{6}\right) \\
{[-]}\end{array}$ & $\begin{array}{l}S\left(\mathrm{C}_{3} \mathrm{H}_{8}\right) \\
{[-]}\end{array}$ & $\begin{array}{l}S(\mathrm{OL}) \\
{[-]}\end{array}$ \\
\hline \multicolumn{7}{|l|}{ Ag loading } \\
\hline $0.5 \mathrm{wt} \% \mathrm{Ag} / \mathrm{SiO}_{2}$ & SD & $\mathrm{H}_{2}$ flow & 0.68 & 0.91 & 0.01 & 0.08 \\
\hline $1 \mathrm{wt} \% \mathrm{Ag} / \mathrm{SiO}_{2}$ & SD & $\mathrm{H}_{2}$ flow & 0.92 & 0.93 & 0.03 & 0.04 \\
\hline $5 \mathrm{wt} \% \mathrm{Ag} / \mathrm{SiO}_{2}$ & SD & $\mathrm{H}_{2}$ flow & 0.90 & 0.091 & 0.04 & 0.05 \\
\hline \multicolumn{7}{|c|}{ Deposition method and activation conditions } \\
\hline \multirow[t]{11}{*}{$1 \mathrm{wt} \% \mathrm{Ag} / \mathrm{SiO}_{2}$} & SD & static air & 0.31 & 0.91 & 0.06 & 0.03 \\
\hline & SD & He flow & 0.82 & 0.86 & 0.08 & 0.06 \\
\hline & SD & NO flow & 0.81 & 0.99 & 0.00 & 0.01 \\
\hline & SD & $\mathrm{O}_{2}$ flow & 0.87 & 0.84 & 0.08 & 0.08 \\
\hline & SD & $\mathrm{H}_{2}$ flow & 0.92 & 0.93 & 0.03 & 0.04 \\
\hline & FD & static air & 0.41 & 0.93 & 0.03 & 0.04 \\
\hline & FD & He flow & 0.79 & 0.89 & 0.05 & 0.06 \\
\hline & FD & NO flow & 0.74 & 0.87 & 0.06 & 0.07 \\
\hline & FD & $\mathrm{O}_{2}$ flow & 0.76 & 0.86 & 0.08 & 0.06 \\
\hline & FD & $\mathrm{H}_{2}$ flow & 0.70 & 0.91 & 0.05 & 0.04 \\
\hline & $C D$ & $\mathrm{H}_{2}$ flow & 0.89 & 0.90 & 0.08 & 0.02 \\
\hline \multicolumn{7}{|l|}{ Carrier } \\
\hline $1 \mathrm{wt} \% \mathrm{Ag} / \mathrm{Al}_{2} \mathrm{O}_{3}$ & SD & $\mathrm{H}_{2}$ flow & 0.58 & 0.91 & 0.06 & 0.03 \\
\hline $1 \mathrm{wt} \% \mathrm{Ag} / \mathrm{TiO}_{2}$ & SD & $\mathrm{H}_{2}$ flow & 0.70 & 0.87 & 0.07 & 0.06 \\
\hline
\end{tabular}

[a] Reaction conditions: $T=473 \mathrm{~K}, \mathrm{H}_{2} / \mathrm{C}_{3} \mathrm{H}_{4}=25, \tau=1 \mathrm{~s}$, and $P=1$ bar.

small and highly dispersed Ag nanoparticles after activation in a flow leads to high propyne conversions (81-92\%) at similar levels of propene selectivity (84-99\%). The specific activation atmosphere $\left(\mathrm{He}, \mathrm{NO}, \mathrm{O}_{2}\right.$, or $\mathrm{H}_{2}$ ) has a relatively minor effect on the performance, as long as the treatment is performed under flowing conditions. Varying the carrier, the $\mathrm{Al}_{2} \mathrm{O}_{3}$ - or $\mathrm{TiO}_{2}$-supported catalysts exhibit lower propyne conversions (58-70\%) than the $\mathrm{Ag} / \mathrm{SiO}_{2}$ catalysts, probably owing to the extremely small $\mathrm{Ag}$ nanoparticles $(2.3-2.8 \mathrm{~nm})$, which are less active in propyne hydrogenation (vide infra). Many other factors, such as strong metal-support interactions $\left(\mathrm{Ag}\right.$ over $\left.\mathrm{TiO}_{2}\right)$, may also be involved in the loss of activity; however, such an investigation is beyond the scope of this article.

The reaction rate and propene selectivity versus the average Ag particle size is displayed in Figure 3. The selectivity to propene is size independent andis stable at approximately $90 \%$. No marked selectivity differences were observed over the broad range of conversions (20-90\%), which emphasizes the extremely selective character of $\mathrm{Ag}$ in propyne hydrogenation. The rate of olefin production per mole of total $\mathrm{Ag}$ reached a maximum for the catalyst with $4.5 \mathrm{~nm}$ particles (this important point is elaborated below). Notably, the same catalysts were tested at three times lower contact times to decrease the degree of conversion and the volcano dependence was analogous, which demonstrates the kinetic relevance of the results independent of conducting the tests under more integral or differential conditions.

The apparent activation energy and reaction orders were determined over $\mathrm{SiO}_{2}$-supported $\mathrm{Ag}$ nanoparticles with variable particle size to understand whether these kinetic parameters are particle size dependent. The results for the catalysts with an average particle size of $4.4 \mathrm{~nm}$ (Figure $1 \mathrm{a}$ ) and $21 \mathrm{~nm}$ (Fig-

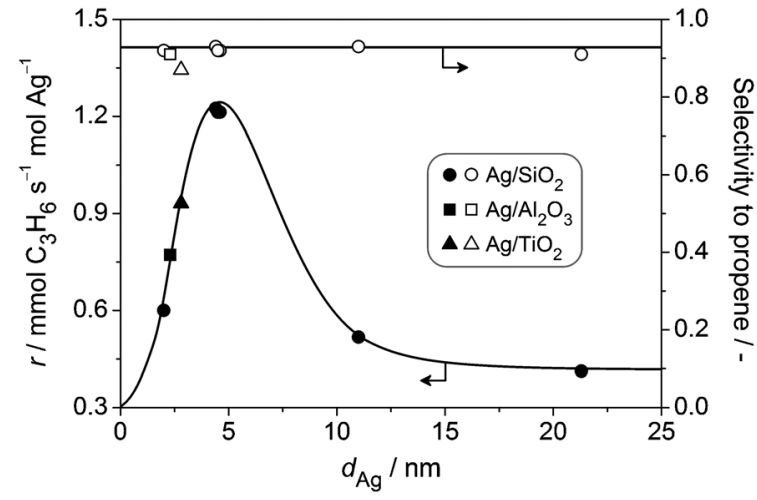

Figure 3. Rate of propene production (solid symbols) and selectivity to propene (open symbols) as a function of the average Ag particle size in the supported catalysts containing $1 \mathrm{wt} \% \mathrm{Ag}$. Reaction conditions: $T=473 \mathrm{~K}$, $\mathrm{H}_{2} / \mathrm{C}_{3} \mathrm{H}_{4}=25, \tau=1 \mathrm{~s}$, and $P=1$ bar.

ure $1 \mathrm{~b}$ ) are shown in Figure 4. The apparent activation energy for propyne hydrogenation is approximately $30 \mathrm{~kJ} \mathrm{~mol}^{-1}$ (Figure $4 \mathrm{a}$ ) and is independent of the $\mathrm{Ag}$ particle size. This value is significantly lower than what has been generally reported for $\mathrm{Pd}, \mathrm{Pt}, \mathrm{Cu}$, and $\mathrm{Ni}\left(50-70 \mathrm{~kJ} \mathrm{~mol}^{-1}\right){ }^{[27-29]}$ Upon increasing the partial $\mathrm{H}_{2}$ pressure, the normalized reaction rate increases over catalysts with extremely different $\mathrm{Ag}$ particles, with a reaction order in $\mathrm{H}_{2}$ between 0 and 1 (Figure $4 \mathrm{~b}$ ). For highly active metals such as $\mathrm{Pd}, \mathrm{Pt}$, and $\mathrm{Ni}$, the reaction order in $\mathrm{H}_{2}$ is generally greater than $1 .^{[27-29]}$ In contrast, upon increasing the partial pressures of propyne, the reaction rate increases (Figure $4 c$ ), which leads to a positive reaction order in propyne in the range of $0-0.3$. The positive dependence of the reaction rate on the partial alkyne pressure is unusual in the partial hydrogenation of alkynes, for which negative values are obtained. ${ }^{[27-29]}$

\section{Hydrogenation mechanism on Ag: Computational approach}

To obtain a molecular-level understanding of the atypical behavior of $\mathrm{Ag}$ in alkyne hydrogenation, periodic DFT calculations were performed on the stepped (211) surface of the metal. Two possible reaction pathways comprising the activation of $\mathrm{H}_{2}$ on the metal surface (HP or dissociative mechanism) and that on the adsorbed alkyne (associative mechanism) were compared (Figure $5 \mathrm{a}$ and Table S1).

At steps and kinks, the elementary steps of the dissociative hydrogenation mechanism are as follows [Steps (D1)-(D7)]:

$$
\begin{aligned}
& \mathrm{C}_{3} \mathrm{H}_{4}+{ }^{*} \rightleftharpoons \mathrm{C}_{3} \mathrm{H}_{4}{ }^{*} \\
& \mathrm{H}_{2}+{ }^{*}+\# \rightleftharpoons \mathrm{H}^{*}+\mathrm{H} \# \\
& \mathrm{C}_{3} \mathrm{H}_{4}{ }^{*}+\mathrm{H}^{*} \rightleftharpoons \mathrm{C}_{3} \mathrm{H}_{5}{ }^{*}+{ }^{*} \\
& \mathrm{C}_{3} \mathrm{H}_{5}{ }^{*}+\mathrm{H}^{*} \rightleftharpoons \mathrm{C}_{3} \mathrm{H}_{6}{ }^{*}+{ }^{*} \\
& \mathrm{C}_{3} \mathrm{H}_{6}{ }^{*} \rightleftharpoons \mathrm{C}_{3} \mathrm{H}_{6}+{ }^{*} \\
& \mathrm{C}_{3} \mathrm{H}_{6}{ }^{*}+\mathrm{H}^{*} \rightleftharpoons \mathrm{C}_{3} \mathrm{H}_{7}{ }^{*}+{ }^{*} \\
& \mathrm{H} \#+{ }^{*} \rightleftharpoons \mathrm{H}^{*}+\#
\end{aligned}
$$



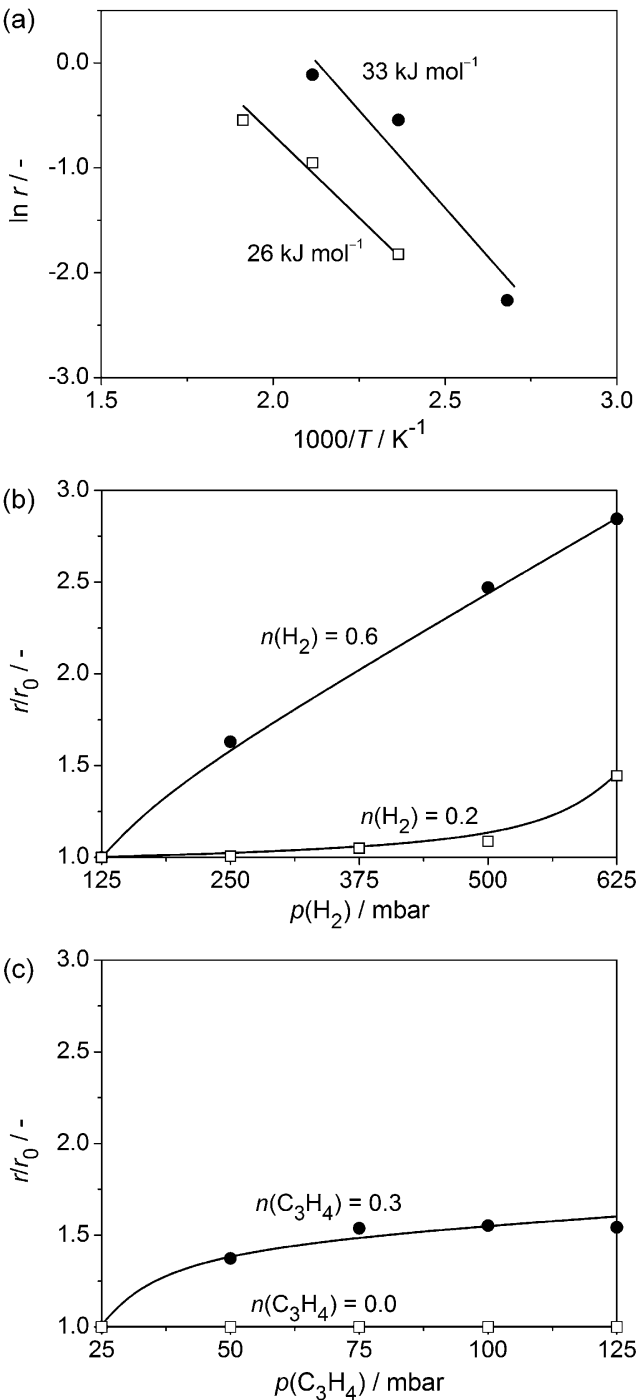

Figure 4. Arrhenius plot for propyne hydrogenation at $T=373-473 \mathrm{~K}, \mathrm{H}_{2} /$ $\mathrm{C}_{3} \mathrm{H}_{4}=25, \tau=1 \mathrm{~s}$, and $P=1$ bar (a). Normalized reaction rate as a function of the inlet partial pressure of $\mathrm{H}_{2}$ (b) and the inlet partial pressure of $\mathrm{C}_{3} \mathrm{H}_{4}$ (c) at $T=473 \mathrm{~K}, \tau=0.3 \mathrm{~s}$, and $P=1$ bar. Solid circles correspond to $1 \mathrm{wt} \% \mathrm{Ag} / \mathrm{SiO}_{2}$ prepared by spray deposition followed by activation in $\mathrm{H}_{2}$ flow at $473 \mathrm{~K}$ for $0.5 \mathrm{~h}$; open squares correspond to $1 \mathrm{wt} \% \mathrm{Ag} / \mathrm{SiO}_{2}$ prepared by spray deposition followed by calcination in static air at $573 \mathrm{~K}$ for $2 \mathrm{~h}$.

The two active sites identified are on the edge of the step $\left({ }^{*}\right)$ and on the lower terrace (\#). The adsorption of propyne (D1) is slightly exoenergetic (by $-0.17 \mathrm{eV}$ ) on step sites and is less favored $(-0.05 \mathrm{eV})$ on flat surfaces. Therefore, propyne adsorbs more strongly on low-coordinated surface sites. This result points to the steps as the active sites of the reaction. Considering the similar adsorption energies of propyne $(-0.17 \mathrm{eV})$ and propene $(-0.14 \mathrm{eV})$, the preferential adsorption of alkynes and the lack of adsorption of alkenes (thermodynamic selectivity ${ }^{[8]}$ cannot be invoked to explain the high propene selectivity observed experimentally. Instead, a sizable kinetic barrier hindering the over-hydrogenation reaction of the olefin is expected. The dissociation of $\mathrm{H}_{2}$ (Step D2; Figure $5 \mathrm{~b}$ ) occurs at the steps of the $\mathrm{Ag}(211)$ surface and leads to two

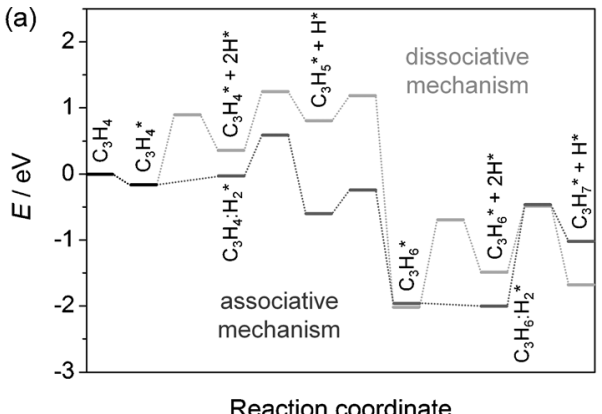

(b)

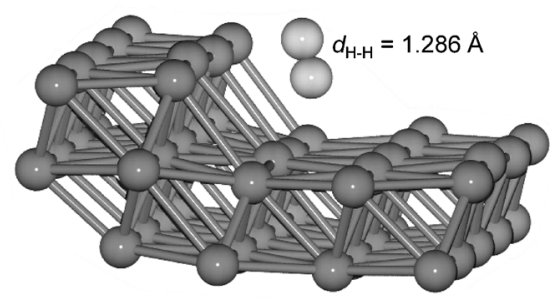

(c)

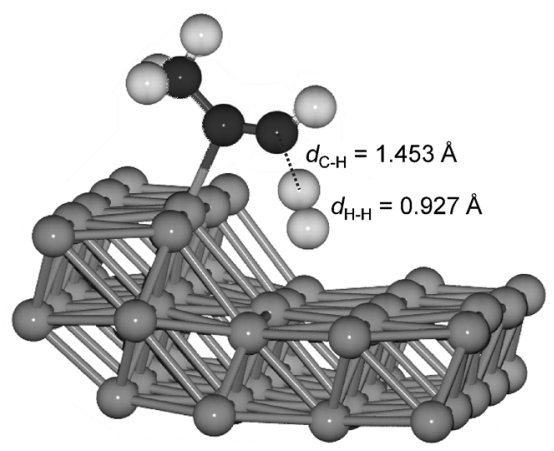

Figure 5. Energy profiles for the hydrogenation of propyne on $\mathrm{Ag}(211)$ (a). Lateral view of the stepped $\mathrm{Ag}(211)$ surface and transition state for $\mathrm{H}_{2}$ activation via the dissociative (b) and associative (c) mechanisms.

adsorbed $\mathrm{H}$ atoms: one at the edge and the other one on the lower surface of the step. This splitting is endoenergetic $(+0.53 \mathrm{eV})$ and has an energy barrier of $1.33 \mathrm{eV}$. The barrier reduces to $1.06 \mathrm{eV}$ upon introduction of the zero-point vibrational energy (ZPVE) contributions, which are required considering the small mass of $\mathrm{H}_{2}$. This large barrier suggests that $\mathrm{H}_{2}$ splitting is the rate-limiting step of this scheme. Notably, this value is much higher for $\mathrm{Ag}$ than for $\mathrm{Au}$ clusters $(0.84 \mathrm{eV})^{[10]}$ and $\mathrm{Cu}(211)(0.50 \mathrm{eV})$. The transfer of the first $\mathrm{H}$ atom (Step D3) to the adsorbed alkyne, forming an alkenyl surface species, is endoenergetic $(+0.44 \mathrm{eV})$, with an energy barrier of $0.88 \mathrm{eV}$, whereas the transfer of the second $\mathrm{H}$ atom (Step D4), forming the adsorbed propene, is highly exoenergetic $(-2.82 \mathrm{eV})$, with an energy barrier of $0.37 \mathrm{eV}$. The adsorbed propene sits parallel to the surface and can easily desorb (Step D5) with an energy of only $0.14 \mathrm{eV}$. The over-hydrogenation reaction (Step D6) is marginally exoenergetic $(-0.19 \mathrm{eV})$ but is hindered by a large energy barrier of $1.01 \mathrm{eV}$; hence, propene desorption is preferred.

The elementary steps of the associative mechanism are as follows [Steps (A1)-(A8)]: 


$$
\begin{aligned}
& \mathrm{C}_{3} \mathrm{H}_{4}+{ }^{*} \rightleftharpoons \mathrm{C}_{3} \mathrm{H}_{4}{ }^{*} \\
& \mathrm{C}_{3} \mathrm{H}_{4}{ }^{*}+\mathrm{H}_{2} \rightleftharpoons \mathrm{C}_{3} \mathrm{H}_{4}: \mathrm{H}_{2}{ }^{*} \\
& \mathrm{C}_{3} \mathrm{H}_{4}: \mathrm{H}_{2}{ }^{*}+\# \rightleftharpoons \mathrm{C}_{3} \mathrm{H}_{5}{ }^{*}+\mathrm{H} \# \\
& \mathrm{C}_{3} \mathrm{H}_{5}{ }^{*}+\mathrm{H} \# \rightleftharpoons \mathrm{C}_{3} \mathrm{H}_{6}{ }^{*}+\# \\
& \mathrm{C}_{3} \mathrm{H}_{6}{ }^{*} \rightleftharpoons \mathrm{C}_{3} \mathrm{H}_{6}+{ }^{*} \\
& \mathrm{C}_{3} \mathrm{H}_{6}{ }^{*}+\mathrm{H}_{2} \rightleftharpoons \mathrm{C}_{3} \mathrm{H}_{6}: \mathrm{H}_{2}{ }^{*} \\
& \mathrm{C}_{3} \mathrm{H}_{6}: \mathrm{H}_{2}{ }^{*}+\# \rightleftharpoons \mathrm{C}_{3} \mathrm{H}_{7}{ }^{*}+\mathrm{H} \# \\
& \mathrm{H} \#+{ }^{*} \rightleftharpoons \mathrm{H}^{*}+\#
\end{aligned}
$$

The coadsorption of propyne (Step A1) and $\mathrm{H}_{2}$ (Step A2) is isoenergetic with respect to the individual reactants (Figure $5 \mathrm{c}$ ). The transition state involves a metastable intermediate $\left(\mathrm{C}_{3} \mathrm{H}_{4}-\mathrm{H}-\mathrm{H}-\mathrm{Ag}\right.$ complex) formed at the step edge of the $\mathrm{Ag}(211)$ surface. The $\mathrm{H}-\mathrm{H}$ and $\mathrm{C}-\mathrm{H}$ bond lengths are 0.927 and $1.453 \AA$, respectively, whereas the $\mathrm{C}-\mathrm{H}-\mathrm{H}$ and $\mathrm{C}-\mathrm{C}-\mathrm{H}$ bond angles are 173 and $140^{\circ}$, respectively. The Bader charges are $0.05|e|$ for the $\mathrm{H}$ atom in contact with the alkyne and $-0.25|e|$ for the $\mathrm{H}$ atom in contact with the $\mathrm{Ag}$ atoms of the lower terrace, which confirms the polarization of the $\mathrm{H}-\mathrm{H}$ bond observed in heterolytic splitting reactions. ${ }^{[21,22]}$ This reaction leads to the formation of an alkenyl and a $\mathrm{H}$-surface species sitting on the terrace (Step A3) and is an exoenergetic $(-0.43 \mathrm{eV})$ process associated with an energy barrier of $1.03 \mathrm{eV}$. Upon ZPVE correction, the energy barrier decreases to $0.74 \mathrm{eV}$. Notably, it is not possible to directly compare the calculated value and the experimental value, because the apparent activation energy depends on the specific set of reaction conditions. ${ }^{[30]}$ However, the large energy required for this step confirms that $\mathrm{H}_{2}$ splitting is hindered on Ag; hence, the hydrogenation requires that an excess of $\mathrm{H}_{2}\left(\mathrm{H}_{2} / \mathrm{C}_{3} \mathrm{H}_{4}=25\right)$ should be applied. The difference in the $\mathrm{C}_{3} \mathrm{H}_{5}+\mathrm{H}$ level between the associative and the dissociative mechanism is due to the corresponding configuration for each step; in the dissociative scheme, the $\mathrm{H}$ atoms are in the top terrace, and in the associative case, the $\mathrm{H}$ atoms are on the lower terrace. The transfer of $\mathrm{H}$ atoms to the alkenyl species leading to propene is both thermodynamically $(-1.00 \mathrm{eV})$ and kinetically $(0.36 \mathrm{eV})$ favored. The formed propene sits perpendicular to the Ag surface and desorbs isoenergetically. Regarding the over-hydrogenation reactions (Steps $A 6$ and A7), desorbed propene needs to readsorb in a flat configuration. The new $\mathrm{H}_{2}$ bond breaking (Step A6) is marginally exoenergetic $(-0.04 \mathrm{eV})$. In contrast, the $\mathrm{H}$ addition forming $\mathrm{C}_{3} \mathrm{H}_{7}{ }^{*}$ is highly endoenergetic $(+0.98 \mathrm{eV})$ and hinders the production of propane. $\mathrm{C}-\mathrm{C}$ coupling reactions are also characterized by high energy barriers, ${ }^{[26]}$ which explain the low degree of oligomerization observed over Ag.

By comparing the energy profiles in Figure $5 \mathrm{a}$, it is clear that the associative mechanism requires lower activation barriers and no high-energy intermediates, which makes this process a much more efficient hydrogenation pathway than the typical $\mathrm{HP}$ mechanism encountered on $\mathrm{Pd}$ and $\mathrm{Ni}$.

\section{Hydrogenation mechanism on Ag: Kinetic analysis and structural aspects}

By following the elementary steps D1-D7 of the HP scheme, it is possible to derive the mathematical expressions for the rate and reaction orders (complete derivations are given in the Supporting Information). Considering that $\mathrm{H}_{2}$ dissociation is the most possible rate-limiting step, the initial rate of the reaction is expressed in Equation (1):

$r \approx k_{2} p\left(\mathrm{H}_{2}\right) \theta\left({ }^{*}\right) \theta(\#) \approx \frac{k_{2} p\left(\mathrm{H}_{2}\right)}{1+K_{1} p\left(\mathrm{C}_{3} \mathrm{H}_{4}\right)}$

The reaction orders in $\mathrm{H}_{2}$ and propyne can be calculated by using Equations (2) and (3):

$$
\begin{aligned}
& n\left(\mathrm{H}_{2}\right)=p\left(\mathrm{H}_{2}\right) \frac{\partial \ln r}{\partial p\left(\mathrm{H}_{2}\right)}=1 \\
& n\left(\mathrm{C}_{3} \mathrm{H}_{4}\right)=p\left(\mathrm{C}_{3} \mathrm{H}_{4}\right) \frac{\partial \ln r}{\partial p\left(\mathrm{C}_{3} \mathrm{H}_{4}\right)}=\frac{K_{1} p\left(\mathrm{C}_{3} \mathrm{H}_{4}\right)}{1+K_{1} p\left(\mathrm{C}_{3} \mathrm{H}_{4}\right)}
\end{aligned}
$$

The latter varies between 0 (with $p\left(\mathrm{C}_{3} \mathrm{H}_{4}\right)=0$ ) and -1 (with $\left.p\left(\mathrm{C}_{3} \mathrm{H}_{4}\right) \rightarrow \infty\right)$.

The initial rate of the reaction that is derived assuming the first $\mathrm{H}_{2}$ addition (step D3) to be the rate-limiting step of the HP scheme is expressed in Equation (4):

$r \approx k_{3} \theta\left(\mathrm{C}_{3} \mathrm{H}_{4}^{*}\right) \theta\left(\mathrm{H}^{*}\right) \approx \frac{k_{3} K_{1} K_{2} p\left(\mathrm{C}_{3} \mathrm{H}_{4}\right) p\left(\mathrm{H}_{2}\right)}{\left[1+K_{1} p\left(\mathrm{C}_{3} \mathrm{H}_{4}\right)+K_{2} p\left(\mathrm{H}_{2}\right)\right]^{2}}$

The reaction orders can be written as shown in Equations (5) and (6):

$$
\begin{aligned}
& n\left(\mathrm{H}_{2}\right)=\frac{1+K_{1} p\left(\mathrm{C}_{3} \mathrm{H}_{4}\right)-K_{2} p\left(\mathrm{H}_{2}\right)}{1+K_{1} p\left(\mathrm{C}_{3} \mathrm{H}_{4}\right)+K_{2} p\left(\mathrm{H}_{2}\right)} \\
& n\left(\mathrm{C}_{3} \mathrm{H}_{4}\right)=\frac{1-K_{1} p\left(\mathrm{C}_{3} \mathrm{H}_{4}\right)+K_{2} p\left(\mathrm{H}_{2}\right)}{1+K_{1} p\left(\mathrm{C}_{3} \mathrm{H}_{4}\right)+K_{2} p\left(\mathrm{H}_{2}\right)}
\end{aligned}
$$

Thus, $n\left(\mathrm{H}_{2}\right) \leq 1$ and $-1 \leq n\left(\mathrm{C}_{3} \mathrm{H}_{4}\right) \leq 0$. In both cases, the HP mechanism cannot account for the positive reaction orders in Figure 4.

By following the elementary steps $\mathrm{A} 1-\mathrm{A} 8$ of the associative mechanism and assuming step $A 3$ to be the rate-determining step, the initial rate of the reaction for the associative mechanism can be calculated by using Equation (7):

$r \approx k_{3} \theta\left(\mathrm{C}_{3} \mathrm{H}_{4}: \mathrm{H}_{2}\right) \theta(\#) \approx \frac{k_{3} K_{1} K_{2} p\left(\mathrm{C}_{3} \mathrm{H}_{4}\right) p\left(\mathrm{H}_{2}\right)}{1+K_{1} p\left(\mathrm{C}_{3} \mathrm{H}_{4}\right)+K_{1} K_{2} p\left(\mathrm{C}_{3} \mathrm{H}_{4}\right) p\left(\mathrm{H}_{2}\right)}$

Thus, the reaction orders are expressed as given in Equations (8) and (9):

$n\left(\mathrm{H}_{2}\right)=\frac{1+K_{1} p\left(\mathrm{C}_{3} \mathrm{H}_{4}\right)}{1+K_{1} p\left(\mathrm{C}_{3} \mathrm{H}_{4}\right)+K_{1} K_{2} p\left(\mathrm{C}_{3} \mathrm{H}_{4}\right) p\left(\mathrm{H}_{2}\right)}$ 


$$
n\left(\mathrm{C}_{3} \mathrm{H}_{2}\right)=\frac{1}{1+K_{1} p\left(\mathrm{C}_{3} \mathrm{H}_{4}\right)+K_{1} K_{2} p\left(\mathrm{C}_{3} \mathrm{H}_{4}\right) p\left(\mathrm{H}_{2}\right)}
$$

Thus, the reaction orders are as follows: $0 \leq n\left(\mathrm{H}_{2}\right) \leq 1$ and $0 \leq n\left(\mathrm{C}_{3} \mathrm{H}_{4}\right) \leq 1$. In contrast to the HP scheme in which $\mathrm{H}_{2}$ and $\mathrm{C}_{3} \mathrm{H}_{4}$ compete for site adsorption and no positive reaction order in hydrocarbon can be observed, in the associative mechanism the cooperative effects due to $\mathrm{H}_{2}$ cleavage on the hydrocarbon are responsible for these positive dependences. The experimental data in Figure 4 are in line with the microkinetic model derived from an associated reaction pathway, which confirms that propyne hydrogenation on $\mathrm{Ag}$ occurs through direct $\mathrm{H}_{2}$ splitting on the adsorbed propyne.

Although DFT calculations in the previous subsection suggest that the reaction occurs at step-like positions, which are highly concentrated on small nanoparticles, experimentally the activity is maximal over approximately $4.5 \mathrm{~nm} \mathrm{Ag}$ whereas smaller nanoparticles are less active (Figure 3 ). To rationalize this aspect, we have used the atomistic Wulff construction to model Ag nanoparticles of different sizes and determine which sites are active in propyne hydrogenation. The investigation has revealed the key role of $\mathrm{B} 5$ sites.

In a nanoparticle, B5 sites alleviate the stress in the formation of line defects between two faces. Two types of B5 structures can be identified on the Ag nanoparticles: at the edge between (111) and (211) faces and within two (211) surfaces (Figure S3a). The presence of the B5 site is identified by characteristic coordination numbers $(z)$ of the $\mathrm{Ag}$ atoms around it. This site is surrounded by two step-edge atoms $(z=7)$, two terrace atoms $(z=9)$, one bottom step atom $(z=10)$, and two bulk atoms $(z=12)$.

By using the atomistic Wulff model, we found that Ag nanoparticles with a core diameter smaller than $3 \mathrm{~nm}$ cannot accommodate any (211) faces. Therefore, they contain no B5 sites, which is in agreement with the low activity measured in Figure 3. The smallest particle with B5 sites is shown in Figure $\mathrm{S} 3 \mathrm{~b}$, and its average size, defined as the average value between the smallest and the largest size of the particle, is $3.0 \mathrm{~nm}$; this particle contains four-atom-long B-type steps in which 24 B5 atoms are located (Table S2). Nevertheless, the presence of fivefold $\mathrm{Ag}$ atoms (shown in red in Figure $\mathrm{S} 3 \mathrm{~b}$ ) could affect the concentration of these active B5 sites because fivefold atoms can easily dislocate and diffuse toward the lowest-energy sites, destroying the particle shape. A larger Ag cluster with 2875 atoms and a particle size of $4.3 \mathrm{~nm}$ is shown in Figure S3c. This nanoparticle contains five-atom-long B-type steps in which 48 B5 sites are situated, and the smallest edge corresponds to two sixfold atoms belonging to hexagonal (111) and (110) faces. Compared to the structure discussed previously, this nanoparticle is significantly more stable under conditions typically used in the hydrogenation experiments. As summarized in Table S2, the highest density of B5 sites is obtained for particle sizes comprised between 3.5 and $4.7 \mathrm{~nm}$. Because B5-type structures on Ag are step sites within the faces of the nanoparticle and not only on its edges, the density of active sites decreases rather slowly for $d_{\mathrm{Ag}}>4.7 \mathrm{~nm}$, without showing the classical $1 / d^{2}$ decrease observed in other metal nanoparticles.

By using the results in Table S2 and the particle size distribution histograms of selected Ag samples (Table 1 and Figure S4), it was possible to re-evaluate the data in Figure 3. The rate of propene production increases as a function of the amount of B5 sites, which indicates the preeminence of B5 sites in the reaction (Figure 6). This result has been confirmed by fitting of

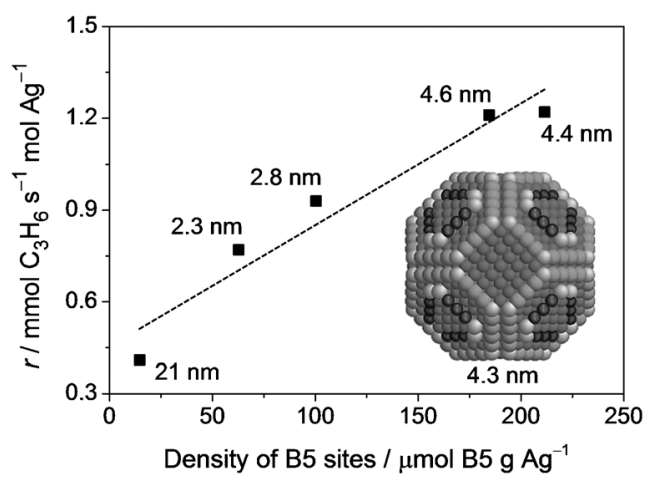

Figure 6. Rate of propene production (solid symbols) as a function of the number of active B5 sites for selected supported catalysts containing 1 wt \% Ag. The line represents the fitting of experimental data obtained through linear regression (equation: $y=0.004 x+0.452$; correlation coefficient, $R^{2}=0.92$ ). The inset shows a Wulff-shaped Ag nanoparticle with a size of $4.3 \mathrm{~nm}$ and, in dark gray, the location of the active $\mathrm{B} 5$ sites. Reaction conditions: $T=473 \mathrm{~K}, \mathrm{H}_{2} / \mathrm{C}_{3} \mathrm{H}_{4}=25, \tau=1 \mathrm{~s}$, and $P=1$ bar.

the experimental results shown in Figure $4 \mathrm{~b}$. The Hertz-Knudsen equation [Eq. (12)] was used to model the adsorption of $\mathrm{H}_{2}$ and propyne. This equation contains the area of one free active site $\left(A_{\text {cat }}\right)$. From DFT calculations, a value of $7.8 \times 10^{-20} \AA^{2}$ is obtained, which corresponds to the area of a site at the step of the nanoparticle. However, the total surface energy is the average between the number of these sites and the number of total surface atoms, and the total surface that can be assigned to these sites is $10^{-18} \AA^{2}$. This value does not account for the real number of active sites. Propyne adsorption is enhanced only at specific step-like (B5) positions. Thus, from the ratio between the constants fitted experimentally (Figure 7) and the DFT values (Table S3), we can identify the amount of B5 sites that are located on this $\mathrm{Ag}$ catalyst $\left(1 \mathrm{wt} \% \mathrm{Ag} / \mathrm{SiO}_{2}\right.$ prepared by spray deposition and activated in $\mathrm{H}_{2}$ flow, with $d_{\mathrm{Ag}}=4.4 \mathrm{~nm}$ ), as shown in Equation (10):

$n(\mathrm{~B} 5)=\frac{k^{\mathrm{DFT}}}{k^{\exp }}$

A B5 site density of $228 \mu \mathrm{mol}$ B5 $\mathrm{g} \mathrm{Ag}^{-1}$ was obtained, which is in excellent agreement with the atomistic simulation data (Figure 6).

\section{Conclusions}

We have studied the gas-phase hydrogenation of propyne over supported Ag nanoparticles with average sizes in the 


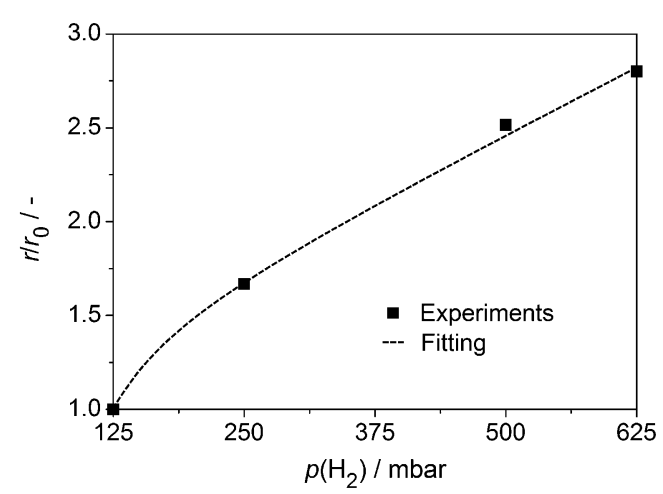

Figure 7. Microkinetic fitting of the data shown in Figure $4 \mathrm{~b}$, representing the normalized reaction rate as a function of the inlet partial pressure of $\mathrm{H}_{2}$ at $T=473 \mathrm{~K}, p\left(\mathrm{C}_{3} \mathrm{H}_{4}\right)=25 \mathrm{mbar}, \tau=1 \mathrm{~s}$, and $P=1$ bar. The data correspond to $1 \mathrm{wt} \% \mathrm{Ag} / \mathrm{SiO}_{2}$ prepared by spray deposition and activation in $\mathrm{H}_{2}$ flow at $473 \mathrm{~K}$ for $0.5 \mathrm{~h}$.

range of $2-20 \mathrm{~nm}$. The catalysts were intrinsically selective toward propene $(\approx 90 \%$ ) regardless of the particle size. Mechanistic and kinetic studies demonstrated that the hydrogenation of propyne on $\mathrm{Ag}$ follows an associative scheme, which involves propyne adsorption on step sites and heterolytic splitting of $\mathrm{H}_{2}$ on the adsorbed hydrocarbon. The reaction rate presented a maximum over the catalysts with $\mathrm{Ag}$ particles of size approximately $4.5 \mathrm{~nm}$. As shown by the atomistic Wulff model, these nanoparticles possess the highest density of B5 sites, which are likely the active centers in the reaction. These findings broaden the mechanistic views of hydrogenation reactions over solid catalysts, going beyond the classical HoriutiPolanyi scheme, and open new directions for understanding related poor $\mathrm{H}_{2}$-splitting hydrogenation catalysts such as $\mathrm{Au}$, $\mathrm{Cu}$, and Fe-Al.

\section{Experimental Section}

\section{Catalyst preparation}

Commercial $\mathrm{SiO}_{2}$ (Evonik, 99.8\%), $\gamma-\mathrm{Al}_{2} \mathrm{O}_{3}$ (Merck, 99\%), and $\mathrm{TiO}_{2}$ (anatase, Sigma-Aldrich, 99.7\%) carriers were used as received. Supported catalysts with a nominal Ag loading of $0.5-5 \mathrm{wt} \%$ were prepared with $\mathrm{AgNO}_{3}$ (Sigma-Aldrich, 99.9\%) as the $\mathrm{Ag}$ precursor. The spray deposition method was performed with a Büchi Mini Spray Dryer B-290 equipped with a two-fluid nozzle of $1.4 \mathrm{~mm}$ in diameter. This technique, pioneered by Yara International, ${ }^{[31]}$ enabled the deposition of metal (oxide) particles with a high degree of dispersion. ${ }^{[32]}$ Silver nitrate $(0.02-0.2 \mathrm{~g})$ was dissolved in deionized water $\left(20 \mathrm{~cm}^{3}\right)$ under magnetic stirring at RT, followed by the addition of the support $(2 \mathrm{~g})$. The resulting suspension was pumped at $3 \mathrm{~cm}^{3} \mathrm{~min}^{-1}$ into the two-fluid nozzle, together with a spray air flow of $0.5 \mathrm{~m}^{3} \mathrm{~h}^{-1}$, which created droplets of 20-30 $\mu \mathrm{m}$. The inlet temperature was set at $493 \mathrm{~K}$, the aspiration rate at $35 \mathrm{~m}^{3} \mathrm{~h}^{-1}$, and the outlet temperature at $383 \mathrm{~K}$. The dried particles were separated by using a cyclone. The impregnation method was performed by dissolving silver nitrate $(0.011 \mathrm{~g})$ in deionized water $\left(1.5 \mathrm{~cm}^{3}\right)$ and by adding the solution to $\mathrm{SiO}_{2}(1.1 \mathrm{~g})$. The paste was dried under freezing and conventional conditions. Freeze drying was performed on a Labconco FreeZone Plus $2.5 \mathrm{~L}$ Cascade Benchtop Freeze Dry System at $40 \mathrm{~K}$ and 0.02 bar. Conventional drying was performed on a Schlenk line at $393 \mathrm{~K}, 10^{-6}$ bar, and under $0.50 \mathrm{~cm}^{3} \mathrm{~min}^{-1}$ of dry air. The samples were activated in static air (at $573 \mathrm{~K}$ for $2 \mathrm{~h}$ ) or by flowing $\left(42 \mathrm{~cm}^{3} \mathrm{~min}^{-1}\right) \mathrm{He}, 1 \mathrm{vol} \% \mathrm{NO} / \mathrm{Ar}$, $5 \mathrm{vol} \% \mathrm{O}_{2} / \mathrm{He}$, and $5 \mathrm{vol} \% \mathrm{H}_{2} / \mathrm{He}$ (at $473 \mathrm{~K}$ for $0.5 \mathrm{~h}$ ). In all cases, the ramp rate was $5 \mathrm{Kmin}^{-1}$. The flow treatments were performed in situ before the hydrogenation tests.

\section{Catalyst characterization}

The Ag content in the solids was determined by inductively coupled plasma optical emission spectroscopy in a Horiba Ultra 2 instrument equipped with a photomultiplier tube detector. Powder XRD patterns were recorded on a PANalytical X'Pert PRO-MPD Diffractometer using Bragg-Brentano geometry and Ni-filtered $\mathrm{CuK}_{\alpha}$ radiation $(\lambda=0.1541 \mathrm{~nm})$. Data were recorded at $2 \theta=3-60^{\circ}$, with an angular step size of $0.05^{\circ}$ and a counting time of $0.75 \mathrm{sstep}^{-1}$. TEM was performed by using a Philips CM12 microscope operated at $100 \mathrm{kV}$. The catalysts were analyzed in their powdered form. The particle size distribution was estimated directly from the transmission electron micrographs by assuming a Gaussian behavior. The dispersion of silver, $D$, defined as the percentage of surface Ag out of the total Ag, was estimated from the TEM particle size distribution by assuming the absence of a silver oxide shell and considering particles to be truncated octahedrons with cubic symmetry. ${ }^{[33]}$ $\mathrm{N}_{2}$ isotherms at $77 \mathrm{~K}$ were measured in a Quantachrome Quadrasorb SI analyzer. Before the measurement, the samples were degassed in vacuum at $473 \mathrm{~K}$ for $2 \mathrm{~h}$. The thermogravimetric analysis (TGA) of the catalyst after propyne hydrogenation was performed by using a Mettler Toledo TGA/DSC 1 Star system under $40 \mathrm{~cm}^{3} \mathrm{~min}^{-1}$ of air by ramping the temperature from 298 to $1173 \mathrm{~K}$ (ramping rate $\left.=10 \mathrm{~K} \mathrm{~min}^{-1}\right)$.

\section{Catalyst testing}

The gas-phase hydrogenation of propyne was studied at ambient pressure in a continuous-flow fixed-bed microreactor (internal diameter $=12 \mathrm{~mm}$ ) using $0.2 \mathrm{~g}$ of catalyst (particle size $=0.2-$ $0.4 \mathrm{~mm}$ ). Catalyst screening was performed at different temperatures (373-523 K) and $\mathrm{H}_{2} / \mathrm{C}_{3} \mathrm{H}_{4}$ ratios (5-25), with a contact time of $\tau=1 \mathrm{~s}$. For this purpose, the partial $\mathrm{H}_{2}$ pressure $\left(p\left(\mathrm{H}_{2}\right)\right)$ was varied in the range of $125-625$ mbar, with a fixed partial $\mathrm{C}_{3} \mathrm{H}_{4}$ pressure of $25 \mathrm{mbar}$, and using $\mathrm{He}$ as the balance gas. To evaluate the formal kinetic dependence of the reaction rate on the reactants, $p\left(\mathrm{C}_{3} \mathrm{H}_{4}\right)$ was varied in the range of $25-125 \mathrm{mbar}$ (with $p\left(\mathrm{H}_{2}\right)=625 \mathrm{mbar}$ ) and $p\left(\mathrm{H}_{2}\right)$ was varied in the range of $125-625 \mathrm{mbar}$ (with $p\left(\mathrm{C}_{3} \mathrm{H}_{4}\right)=$ $25 \mathrm{mbar}$ ) at $T=473 \mathrm{~K}$ and $\tau=0.3 \mathrm{~s}$. Under these conditions, the conversion of propyne was less than $20 \%$. All the catalytic data were measured in steady state, and the performance was stable during at least $5 \mathrm{~h}$ on stream. Tests with different sieve fractions in the particle size range of $0.15-0.6 \mathrm{~mm}$ and different total volumetric flows $\left(3-84 \mathrm{~cm}^{3} \mathrm{~min}^{-1}\right)$ at constant $\tau=1 \mathrm{~s}$ were conducted to discard internal and external mass transport limitations. The temperature gradients along the bed were less than $5 \mathrm{~K}$. The composition of the gas at the reactor outlet was analyzed with an online gas chromatograph (Agilent GC7890A) equipped with a GS-GasPro column and a flame ionization detector. The conversion of propyne, $X\left(\mathrm{C}_{3} \mathrm{H}_{4}\right)$, was determined as the amount of reacted alkyne divided by the amount of alkyne at the reactor inlet. The selectivity to propene $\left(S\left(\mathrm{C}_{3} \mathrm{H}_{6}\right)\right)$ and propane $\left(S\left(\mathrm{C}_{3} \mathrm{H}_{8}\right)\right)$ was calculated as the amount of product formed divided by the amount of alkyne converted. The selectivity to oligomers (OL) was obtained by using the carbon balance, $\mathrm{S}(\mathrm{OL})=1-\mathrm{S}\left(\mathrm{C}_{3} \mathrm{H}_{6}\right)-\mathrm{S}\left(\mathrm{C}_{3} \mathrm{H}_{8}\right)$. It was assumed that all missing carbon atoms in the balance comprised oligomers. TGAs 
of the catalysts after propyne hydrogenation enabled the closing of the carbon balance to $97 \mathrm{wt} \%$, and the transmission electron micrograph of these samples did not reveal the presence of coke deposits (Figure S1).

\section{Density functional theory}

DFT calculations based on slabs were performed with the Vienna $\mathrm{Ab}$ initio Simulation Package code $\mathrm{C}^{[34]}$ and the revised PerdewBurke-Ernzerhof (RPBE) functional. ${ }^{[35]}$ To account for dispersion interactions, the Grimme-based correction was used. ${ }^{[36-38]}$ This approach ensured a correct treatment of the gas-phase reference while including dispersion contributions. Core electrons were replaced by projector-augmented wave (PAW) pseudopotentials, ${ }^{[39]}$ whereas valence electrons were expanded in plane waves with a kinetic cutoff energy of $400 \mathrm{eV}$. As the planar Ag(111) surface does not interact with reactants, a stepped (211) facet was used to represent the active sites of the $\mathrm{Ag}$ nanoparticles. The slab contained nine metal layers, in a $p(2 \times 1)$ supercell for the adsorption of the individual molecules and in a $p(4 \times 1)$ supercell when assessing hydrogenation and oligomerization paths. In all cases, the active site was surrounded by empty positions, thus excluding lateral interactions. The $k$-point sampling was derived from the Monkhorst-Pack scheme. ${ }^{[40]}$ Transition states were located through the climbingimage version of the nudged elastic band (CI-NEB) algorithm. ${ }^{[41]}$ The vibrational analysis of the potential transition state structures was performed to fully characterize the saddle points. For this reason, the numerical Hessian matrix, obtained with a displacement of $0.02 \AA$ for each degree of freedom, was diagonalized to obtain the corresponding eigenvalues and eigenmodes, and it showed a single imaginary frequency.

\section{Kinetic analysis and structural models}

The rate of the elementary steps was determined by multiplying the coverage of reactants by the corresponding rate coefficient, $k$ $\left(\mathrm{s}^{-1}\right)$, which was computed according to the transition state theory of Eyring, Evans, and Polanyi [Eq. (11)]:

$k=k_{0} \exp \left(-\frac{E_{\mathrm{a}}}{k_{\mathrm{B}} T}\right) \approx 10^{13} \exp \left(-\frac{E_{\mathrm{a}}}{k_{\mathrm{B}} T}\right)$

Here, $k_{0}$ is the preexponential factor, taken as $10^{13}$ for all the reactions on the surface; $E_{\mathrm{a}}$ is the ZPVE-corrected activation energy; $k_{\mathrm{B}}$ is the Boltzmann constant; and $T$ is the temperature. The rate of adsorption steps (Steps A1, A2 and D1, D2) was calculated by using the Hertz-Knudsen equation [Eq. (12)].

$r_{\mathrm{ads}}=\frac{p(i) \theta\left(^{*}\right)}{\sqrt{2 \pi m(i) k_{\mathrm{B}} T}} A_{\mathrm{cat}}$

Here, $p(I)$ and $m(I)$ are the partial pressure and the mass of the gas phase species $i$, respectively, and $A_{\text {cat }}$ is the area of one free active site. Site balances were used to ensure that the number of sites on a catalyst is constant; hence, all coverages add up to unity. The microkinetic fitting was performed by using a plug-flow reactor model. This is reasonable because the Péclet number, defined as the ratio between the rates of axial advection and radial diffusion, was always greater than 20 .

By using the atomistic Wulff method, we constructed structural models for the equilibrium shape of small and large Ag nanoparticles. The Wulff construction was based on the simple geometrical criterion that under thermodynamic equilibrium conditions, a given quantity of matter will attain a shape that minimizes the total surface energy of the system, which is the shape in which the distance of each face from the center is proportional to the surface tension of the respective surface. The original version of the model is continuous and size independent. Therefore, the method might indicate the formation of highly active surfaces for structures for which there is not enough space to generate an open facet. The atomistic Wulff construction ${ }^{[42-44]}$ mitigates this problem, because it further required that the enclosed volume had to fit the individual $\mathrm{Ag}$ atoms. This approach has been used to predict the equilibrium shape of $\mathrm{Ru}^{[42]}$ and $\mathrm{Au}^{[43,44]}$ nanoparticles interacting with the surrounding environment.

\section{Acknowledgements}

This study was financially supported by ETH Zurich, the Ministerio de Economía y Competitividad (Spain) (CTQ2012-33826), and the ICIQ Foundation. We are grateful to Dr. S. Mitchell and Dr. F. Krumeich for performing electron microscopic analyses. The Electron Microscopy Centre of the Swiss Federal Institute of Technology (EMEZ) is acknowledged for the use of their facilities. BSC-RES is thanked for providing generous computational resources.

Keywords: B5 sites $\cdot \mathrm{H}_{2}$ activation - hydrogenation mechanistic studies $\cdot$ nanoparticles $\cdot$ olefins $\cdot$ silver

[1] H. F. Rase in Handbook of Commercial Catalysts: Heterogeneous Catalysts, CRC Press, Boca Raton, 2000, p. 110.

[2] S. Nishimura in Handbook of Heterogeneous Catalytic Hydrogenation for Organic Synthesis, Wiley, New York, 2001, p. 63.

[3] M. L. Derrien in Catalytic Hydrogenation, Stud. Surf. Sci. Catal., Vol. 27 (Ed.: L. Červený), Elsevier, Amsterdam, 1986, p. 613.

[4] D. Teschner, J. Borsodi, A. Wootsch, Z. Révay, M. Hävecker, A. Knop-Gericke, S. D. Jackson, R. Schlögl, Science 2008, 320, 86.

[5] J. A. Anderson, J. Mellor, R. P. K. Wells, J. Catal. 2009, 261, 208

[6] D. Mei, M. Neurock, C. M. Smith, J. Catal. 2009, 268, 181.

[7] M. Crespo-Quesada, A. Yarulin, M. Jin, Y. Xia, L. Kiwi-Minsker, J. Am. Chem. Soc. 2011, 133, 12787.

[8] F. Studt, F. Abild-Pedersen, T. Bligaard, R. Z. Sørensen, C. H. Christensen, J. K. Nørskov, Science 2008, 320, 1320.

[9] M. Armbrüster, K. Kovnir, M. Behrens, D. Teschner, Y. Grin, R. Schlögl, J. Am. Chem. Soc. 2010, 132, 14745.

[10] B. Bridier, N. López, J. Pérez-Ramírez, Dalton Trans. 2010, 39, 8412.

[11] G. Kyriakou, M. B. Boucher, A. D. Jewell, E. A. Lewis, T. J. Lawton, A. E. Baber, H. L. Tierney, M. Flytzani-Stephanopoulos, E. C. H. Sykes, Science 2012, 335, 1209.

[12] M. Armbrüster, K. Kovnir, M. Friedrich, D. Teschner, G. Wowsnick, M. Hahne, P. Gille, L. Szentmiklósi, M. Feuerbacher, M. Heggen, F. Girgsdies, D. Rosenthal, R. Schlögl, Y. Grin, Nat. Mater. 2012, 11, 690.

[13] J. Horiuti, M. Polanyi, Trans. Faraday Soc. 1934, 30, 1164.

[14] R. L. Augustine, J. F. van Peppen, Ann. N. Y. Acad. Sci. 1970, 172, 244.

[15] B. Hammer, J. K. Nørskov, Nature 1995, 376, 238.

[16] G. Lee, E. W. Plummer, Phys. Rev. B 1995, 51, 7250.

[17] A. Montoya, A. Schlunke, B.S. Haynes, J. Phys. Chem. B 2006, 110, 17145 .

[18] A. B. Mohammad, K. H. Lim, I. V. Yudanov, K. M. Neyman, N. Rösch, Phys. Chem. Chem. Phys. 2007, 9, 1247.

[19] S. Klacar, H. Grönbeck, Catal. Sci. Technol. 2013, 3, 183.

[20] A. Sárkány, Z. Révay, Appl. Catal. A 2003, 243, 347.

[21] D. Balcells, E. Clot, O. Eisenstein, Chem. Rev. 2010, 110, 749.

[22] C. Copéret, Chem. Rev. 2010, 110, 656.

[23] V. Amir-Ebrahimi, J. J. Rooney, Catal. Lett. 2009, 127, 20.

[24] T. Vergunst, F. Kapteijn, J. A. Moulijn, Appl. Catal. A 2001, 213, 179.

[25] T. M. Eggenhuisen, P. Munnik, H. Talsma, P. E. de Jongh, K. P. de Jong, J. Catal. 2013, 297, 306. 
[26] DFT predicts that oligomers are mostly formed via the $\mathrm{C}-\mathrm{C}$ coupling of propene. The coupling of two propenes $\left(2 \mathrm{C}_{3} \mathrm{H}_{6}{ }^{*} \rightleftarrows \mathrm{C}_{6} \mathrm{H}_{12}{ }^{* *}\right.$, with $\Delta E=$ $-0.51 \mathrm{eV}$ and an energy barrier of $0.51 \mathrm{eV}$ ) is favored over the coupling of two propynes $\left(2 \mathrm{C}_{3} \mathrm{H}_{4}{ }^{*} \rightleftarrows \mathrm{C}_{6} \mathrm{H}_{8}{ }^{* *}\right.$, with $\Delta E=-0.61 \mathrm{eV}$ and an energy barrier of $1.25 \mathrm{eV}$ ). The involvement of propene in the oligomerization reaction is experimentally confirmed, as shown in Figure S12.

[27] G. C. Bond, P. B. Wells, J. Catal. 1966, 5, 65.

[28] R. S. Mann, S. C. Naik, Can. J. Chem. 1968, 46, 623.

[29] G. C. Bond in Metal-catalysed Reactions of Hydrocarbons, Springer, New York, 2005, p. 421.

[30] D. Teschner, G. Novell-Leruth, R. Farra, A. Knop-Gericke, R. Schlögl, L. Szentmiklósi, M. Hevia, H. Soerijanto, R. Schomäcker, J. Pérez-Ramírez N. López, Nat. Chem. 2012, 4, 739.

[31] A. H. Øygarden, J. Pérez-Ramírez, D. Waller, K. Schöffel, D. Brackenbury WO2004/110622, 2004.

[32] M. Santiago, A. Restuccia, F. Gramm, J. Pérez-Ramírez, Microporous Mesoporous Mater. 2011, 146, 76.

[33] R. van Hardeveld, F. Hartog, Surf. Sci. 1969, 15, 189.

[34] G. Kresse, J. Hafner, Phys. Rev. B 1993, 47, 558.
[35] B. Hammer, L. B. Hansen, J. K. Nørskov, Phys. Rev. B 1999, 59, 7413.

[36] S. Grimme, J. Comput. Chem. 2006, 27, 1787.

[37] T. Bucko, S. Lebegue, J. G. Angyan, J. Hafner, J. Phys. Chem. A 2010, 114, 11814.

[38] V. G. Ruiz, W. Liu, E. Zojer, M. Scheffler, A. Tkatchenko, Phys. Rev. Lett. 2012, 108, 146103.

[39] P. E. Blöchl, Phys. Rev. B 1994, 50, 17953.

[40] H. J. Monkhorst, J. D. Pack, Phys. Rev. B 1976, 13, 5188

[41] G. Henkelman, B. P. Uberuaga, H. Jonsson, J. Chem. Phys. 2000, 113, 9901.

[42] K. Honkala, A. Hellman, I. N. Remediakis, A. Logadottir, A. Carlsson, S. Dahl, C. H. Christensen, J. K. Nørskov, Science 2005, 307, 555.

[43] G. D. Barmparis, I. N. Remediakis, Phys. Rev. B 2012, 86, 085457.

[44] G. D. Barmparis, K. Honkala, I. N. Remediakis, J. Chem. Phys. 2013, 138, 064702.

Received: July 15, 2013

Published online on September 11, 2013 